\title{
Preocupações e Tendências Contemporâneas da Pesquisa em Etnomatemática presentes na Lista Eletrônica de Discussões do International Study Group on Ethnomathematics ${ }^{1}$
}

\author{
Current concerns and trends of research in Ethnomathematics showed in the electronic \\ mailing list of the International Study Group on Ethnomatematics
}

\author{
Roger Miarka \\ romiarka@gmail.com
}

\begin{abstract}
Resumo
Em 2014 a Etnomatemática comemorou trinta anos desde o marco de criação de seu espaço político na Educação Matemática: o pronunciamento de Ubiratan D'Ambrosio, em 1984, no $5^{\circ}$ Congresso Internacional de Educação Matemática, em Adelaide, Austrália (D'AMBROSIO, 1984). No rastro desse aniversário, investigamos as tendências e preocupações contemporâneas da pesquisa em Etnomatemática após esse período de trinta anos de amadurecimento. Para isso, analisamos as mensagens trocadas entre 25 de novembro de 2008 e 18 de dezembro de 2014 na lista eletrônica de discussões do International Study Group on Ethnomathematics, entendendo-a como um lócus de encontro virtual entre pesquisadores da área. Metodologicamente, assumimos uma abordagem fenomenológica (BICUDO, 1999, 1999a, MARTINS; BICUDO, 1989), selecionando Unidades de Significado junto à interrogação "Para onde apontam as tendências e preocupações de pesquisa da Etnomatemática anunciadas na lista eletrônica de discussões do International Study Group on Ethnomathematics?", analisando suas possíveis convergências por meio de reduções fenomenológicas. Nesse processo, articulamos quatro categorias abrangentes, nomeadas de "Lista de divulgação: de eventos, de artigos, de pessoas", "A Lista como Espaço Político", "A Lista e seus Grupos de Interesse" e "A Lista e seus Movimentos de Teorização". Neste artigo, apresentamos a abertura dessas categorias por meio de um discurso inteligível e uma síntese de transição sobre o significado dessas categorias no cenário da Etnomatemática.
\end{abstract}

Palavras-chave: Etnomatemática; Fenomenologia; ISGEm; Lista de Discussão.

\begin{abstract}
In 2014 Ethnomathematics celebrates thirty years since the creation of its political space in Mathematics Education: the pronouncement of Ubiratan D'Ambrosio, in 1984, at the 5th International Congress on Mathematical Education, Adelaide, Australia (D' AMBROSIO, 1984). Taking this anniversary into account, this research aimed to investigate current trends and concerns of research in Ethnomathematics after this thirty-year period of maturity. For this, we analyzed the messages exchanged between the 25 th of November of 2008 and the 18th of December of 2014 in the electronic discussion list of the International Study Group on Ethnomathematics, understanding it as a locus of virtual meeting among researchers in Ethnomathematics. Methodologically, we assumed a phenomenological approach (BICUDO, 1999, 1999a, MARTINS; BICUDO, 1989), in which we selected Discursive Significant Units through our guideline question "What are the trends and concerns of Ethnomathematics research announced in the electronic mailing list of the International Study Group on Ethnomathematics?", analyzing the possible convergences through phenomenological reductions. Then we articulated four broaden categories, called "List of Divulgation: of events, of articles, of people", "The List as a Political Space", "The List and its Groups of Interest" and "The List and its Moviments of Theorization", that will be presented in this text. Besides that, we discuss their meaning in a broaden scenery of Ethnomathematics.
\end{abstract}

Keywords: Ethnomathematics; Phenomenology; ISGEm; Electronic Mailing Discussion List.

\footnotetext{
${ }^{1}$ Pesquisa com apoio da Fundação de Amparo à Pesquisa do Estado de São Paulo (FAPESP), processo 2014/09000-6.
} 


\title{
Introdução: apresentando a Etnomatemática ${ }^{2}$ como campo de pesquisa e estabelecendo a problemática que guiou a pesquisa
}

Em 2014 a Etnomatemática, como região de inquérito, comemorou 30 anos desde o marco de criação de seu espaço político na Educação Matemática: o pronunciamento de Ubiratan D'Ambrosio, em 1984, no $5^{\circ}$ Congresso Internacional de Educação Matemática, em Adelaide, Austrália (D'AMBROSIO, 1984).

Desde então a área de pesquisa cresceu muito, e nichos de seu estudo podem, atualmente, ser encontrados por todo o mundo. O Brasil, em especial, é considerado um dos países com maior tradição de pesquisa nessa área, que tem crescido de maneira expressiva. Um indício disso se mostra ao constatarmos que, em setembro de 2012, encontravam-se cadastrados no diretório de pesquisas do Conselho Nacional de Desenvolvimento Científico e Tecnológico $(\mathrm{CNPq}) 54$ grupos de pesquisa que a assumiam como frente de investigação (CNPQ, 2012); em fevereiro de 2014 este número subiu para 69 (CNPQ, 2014).

A área, como se sabe, é vasta e, em meio à diversidade de focos de pesquisa, perguntamo-nos, após seu aniversário de 30 anos, acerca de suas preocupações, em termos do já produzido e das suas solicitações.

Ao buscarmos um possível lócus de estudo dessas preocupações em que pudéssemos ter acesso ao discurso de pesquisadores em Etnomatemática com espaço para a diversidade, elegemos o International Study Group on Ethnomathematics (ISGEm), por ter sido criado logo após o marco político de criação da Etnomatemática por seus próprios idealizadores.

\begin{abstract}
The International Study Group on Ethnomathematics was founded in 1985 by math educators Gloria Gilmer, Ubiratan D'Ambrosio, Gil Cuevas, and Rick Scott. Since that time it has sponsored programs and business meetings at the annual conferences of the National Council of Teachers of Mathematics (U.S.A.) and at the International Congress of Mathematics Education. In 1990 ISGEm became an affiliate of the U.S. National Council of Teachers of Mathematics. (ISGEM, 2016)
\end{abstract}

No que se refere ao discurso de seus participantes, elegemos a lista eletrônica de mensagens desse grupo, mantida até os dias de hoje com possibilidade irrestrita e gratuita de inscrição.

$\mathrm{Na}$ esteira desse movimento, esta pesquisa se propôs a focar nosso olhar nas mensagens trocadas entre os membros da lista eletrônica de discussões do ISGEm, de modo a buscar por convergências e distanciamentos no anunciado nas mensagens, em busca das tendências e preocupações no horizonte de pesquisas da Etnomatemática do grupo que participa dessa lista, sendo norteada pela seguinte pergunta:

\footnotetext{
${ }^{2}$ Neste artigo, optamos por grafar Etnomatemática com letra maiúscula para destacar que nosso foco de estudo a toma como área de pesquisa. Julgamos importante elaborar essa observação por termos ciência que há movimentos etnomatemáticos que escapam de sua conformação como área.
} 


\section{Para onde apontam as tendências e preocupações contemporâneas da pesquisa em}

\section{Etnomatemática anunciadas na lista eletrônica de discussões do International Study Group on Ethnomathematics?}

Junto a esta pergunta diretriz, além de buscar e analisar as convergências temáticas acerca das tendências e preocupações da pesquisa em Etnomatemática, ao tomar a lista de discussões da ISGEm como lócus de estudo, procuramos compreender os modos como a lista de discussões do ISGEm opera no que se refere à pesquisa em Etnomatemática. Com isso, buscamos constituir uma visão panorâmica dos modos como a Etnomatemática se presentifica nessa lista, apresentando seus temas de convergência que dizem para onde aponta esta região de inquérito após trinta anos desde sua constituição.

\section{Estabelecendo um percurso metodológico para a pesquisa}

Para responder a pergunta anunciada, procedemos inicialmente com a seleção de um recorte do período a ser estudado. Como nossa intenção tratava de analisar as preocupações e tendências contemporâneas da pesquisa em Etnomatemática presentes na lista eleita, entendidas como tentáculos enraizados em um solo de pesquisas já realizadas que se lançavam ao futuro em expectativas, consideramos que o recorte a ser estudado deveria priorizar as discussão atuais, sem deixar de carregar consigo os rastros de debates de um passado próximo que as motivassem.

Tendo isso em vista, optamos por analisar as mensagens trocadas entre 25 de novembro de 2008 a 18 de dezembro de 2014. Nosso corpo de dados se constituiu por 933 mensagens e 112 arquivos anexos. Para organizá-los, criamos um grupo de mensagens em torno de cada assunto juntamente a uma planilha-mãe que os gerenciava, composta pelos campos "grupo, título, ordem da mensagem dentro do grupo, anexos, data, autor, e-mail do autor, universidade/país de origem do autor". Obtivemos, assim, 441 grupos de e-mails, organizados em arquivos distintos. Segue o quadro 01 com nosso corpo de dados:

Quadro 01: Corpo de Dados da Pesquisa

\begin{tabular}{|l|l|}
\hline Data de Início & $25 / 11 / 2008$ \\
\hline Data Final & $18 / 12 / 2014$ \\
\hline Mensagens & 933 \\
\hline Anexos & 112 \\
\hline Grupos de mensagens & 441 \\
\hline Participantes da lista & 214 \\
\hline Participantes ativos & 96 \\
\hline Número de países de proveniência dos participantes & 20 \\
\hline
\end{tabular}

Fonte: Elaborado pelo autor. 
Além disso, enviamos uma mensagem para a lista consultando seus participantes sobre a utilização das mensagens como dados para a pesquisa. A mensagem foi muito bem recebida por seus subscribers ${ }^{3}$, que consideraram o trabalho fundamental, podendo vir a tornar-se um importante repositório para discussões em torno de Etnomatemática, evitando que o já dito se "perdesse ao vento".

Roger-That sounds like a very useful project. I hope you will have some results to report at the ICME-13 in

Hamburg next year. (Mensagem de subscriber da Lista)

Nice to know that not all we wrote is gone with the wind (an ethnomathematical forum and archive still missing). (Mensagem de subscriber da Lista)

Para a análise desse material, assumimos uma postura fenomenológica, por considerar que a fenomenologia:

[...] como método de investigação, fundamenta procedimentos rigorosos de pesquisa, [...] trabalha no real vivido, buscando a compreensão disso que somos e que fazemos - cada um de nós e todos em conjunto. Buscando o sentido e o significado mundano das teorias e das ideologias e das expressões culturais e históricas (BICUDO, 1999, p. 12-13).

Além disso, a fenomenologia, abriu-nos a possibilidade de tratar daquilo que se mostra, buscando compreensões do fenômeno, entendido como o encontro daquele que vê com aquilo que se mostra, no caso desta pesquisa, o encontro do pesquisador com as mensagem trocadas em uma lista de discussões sobre Etnomatemática em busca de compreensões acerca das preocupações e tendências contemporâneas desse programa de pesquisa.

Com os dados organizados, de acordo com um referencial fenomenológico (MARTINS; BICUDO, 1989, BICUDO, 1999, 1999a), prosseguimos com a seleção de trechos significativos - que chamamos de Unidades de Significado (US) - com o objetivo de responder a pergunta "para onde apontam tendências e preocupações contemporâneas da pesquisa em Etnomatemática anunciadas na lista eletrônica de discussões do International Study Group on Ethnomathematics?" e abrir a visão de um horizonte de compreensões do dito.

Para isso, construímos uma tabela para cada grupo de mensagens, destacando que, ainda que um grupo de mensagens tivesse um disparador de ideias iniciais, as mensagens que se seguiam não necessariamente mantinham o assunto. Desse modo, para organizar nossas Unidades de Significados, sentimos necessidade de articular sinteticamente os seguintes campos: "objetivo inicial da mensagem", "uma codificação", "ideia central" e "síntese compreensiva do dito", de acordo com o exemplo que se segue (Quadro 02):

\footnotetext{
${ }^{3}$ Subscriber refere-se a um participante inscrito na Lista.
} 
Quadro 02: Análise de uma Unidade de Significado

\begin{tabular}{|l|l|l|}
\hline \multicolumn{2}{|c|}{ Grupo 006 } \\
\hline Objetivo Inicial & \multicolumn{2}{|c|}{ Divulgação de livro } \\
\hline Código US & Ideia central & Síntese \\
\hline 6.1 .1 & $\begin{array}{l}\text { Apresentação de } \\
\text { prática cultural }\end{array}$ & Apresentação da prática de cestaria de um grupo de moçambicanos. \\
\hline 6.1 .2 & $\begin{array}{l}\text { Potencialidades do } \\
\text { estudo de prática } \\
\text { cultural }\end{array}$ & $\begin{array}{l}\text { As "cestas didáticas" e os modos como o grupo de praticantes } \\
\text { trabalham podem estimular a reflexão sobre a relação entre educação e } \\
\text { cultura. O livro apresenta diferentes problemas que podem ajudar o } \\
\text { professor a explorar a matemática na prática de cestaria. }\end{array}$ \\
\hline
\end{tabular}

Fonte: Elaborado pelo autor.

Nesse processo, atentando-nos à problemática proposta e caminhando em direção ao seu esclarecimento, o movimento de redução fenomenológica foi sendo efetuado. A pesquisa, por ser fenomenológica, ocorreu por reduções sucessivas.

Nessa pesquisa, a redução fenomenológica constituiu um movimento em que intencionamos deixar em suspeição e sob atenção nossas crenças prévias e pré-conceitos sobre Etnomatemática, estando alerta para o que se mostra, transcendendo a barreira de fragilidade e ingenuidade de nossas próprias concepções sobre essa região de inquérito, mantendo-nos atentos às maneiras como ela se mostra em termos de preocupações e tendências. Salientamos que não se trata de um descarte de concepções prévias, mas de estar atento ao modo como se tornam presentes na compreensão do fenômeno, colocando-as sob suspeita. Esse movimento é essencial visto que, como indica Bicudo (1999, p.22), "pela redução os atos da consciência expõem-se, ou seja, toma-se ciência deles de modo que, pela reflexão, seu componente, são explicitadas as raízes cognitivas das próprias afirmações".

Nesse movimento de redução, as Unidades de Significado, mostrando-se com sentido, foram agrupadas e, ao mostrarem-se convergentes, foram articuladas em categorias abertas abrangentes.

Nessa perspectiva fenomenológica de conduzir a pesquisa, as categorias são chamadas abrangentes ou abertas em contraposição às categorias como concebidas aristotelicamente. Categorias são, segundo Husserl, grandes regiões, não apriorísticas, de generalizações (MARTINS; BICUDO, 1989, p. 80-81).

Seguimos debruçando-nos sobre a estrutura encontrada, em busca de um trabalho de análise do exposto e de reunião do compreendido, em direção a uma teorização, expondo um discurso inteligível e refletido sobre as convergências encontradas. 


\section{As categorias abrangentes}

Com o movimento efetuado, articulamos quatro categorias abertas, em que buscamos despersonalizar as ideias apresentadas, em direção a uma transcendência do exposto pelos subscribers. Nesse processo, articulamos quatro categorias - "A Lista de Divulgação: de eventos, de artigos, de pessoas", "A Lista e seus Grupos de Interesse", "A Lista como Espaço Público-Político" e "A Lista e seus Movimentos de Teorização" -, que serão abertas a seguir por meio de discursos inteligíveis.

\section{Lista de divulgação: de eventos, de artigos, de pessoas}

Nesta categoria, a Lista se mostra como um mecanismo pragmático para divulgar ideias, eventos, livros, artigos, periódicos, projetos educacionais e de pesquisa, a pesquisa de seus participantes e, especialmente, os próprios participantes.

A divulgação da pesquisa e das atividades realizadas pelos próprios participantes é um exercício bastante frequente. Um exemplo disso é que a maior parte dos arquivos anexados às mensagens são de autoria do próprio autor da mensagem.

É preciso destacar, contudo, que a Lista não é composta exclusivamente por pesquisadores, de modo que são também divulgados projetos educacionais e eventos centrados em práticas culturais, não necessariamente presentes em universidades.

Uma discussão constante na Lista trata da busca pela realização de um repositório com trabalhos em Etnomatemática. O espaço para tal repositório chegou a ser constituído na página pessoal de um dos membros mais atuantes do grupo, porém, contém links atualmente inativos ${ }^{4}$. Tal iniciativa parece bastante importante, por tentar transcender a própria Lista e sua fugacidade - na medida em que as mensagens se perdem em sua temporalidade - e ao próprio grupo de discussões. Afinal, um repositório mantém-se à espera do acesso e da mobilização de pessoas que não necessariamente participam da Lista.

Há dois periódicos que mantêm a divulgação de suas novas edições de maneira constante: a "Revista Latinoamericana de Etnomatemática" e o "Journal of Mathematics and Culture $^{6} "$, ambos direcionados a pesquisadores em Etnomatemática.

A Lista também veicula, de maneira rotineira, o jornal NASGEm News - promovido pelo North American Study Group on Ethnomathematics (NASGEm), um subgrupo do International Study Group on Ethnomathematics (ISGEm) -, que publica artigos breves sobre

\footnotetext{
${ }^{4}$ Esse repositório foi constituído em $<$ http://isgem.rpi.edu/pl/ethnomathematics $>$. O acesso em 10 de maio de 2016 já apresentava links corrompidos.

${ }^{5}$ Disponível em $<$ http://www.revista.etnomatematica.org/index.php/RLE $>$

${ }^{6}$ Disponível em $<$ http://nasgem.rpi.edu/pl/journal-mathematics-culture-s37>
} 
Etnomatemática para um público abrangente, não necessariamente de pesquisadores nessa área.

Notamos que a Lista trata assuntos mais relacionados ao NASGEm do que ao ISGEm como um todo, ou seja, parece atender mais a um subgrupo do grupo inicial proposto para a Lista.

A Lista também se mostra como um importante mecanismo de divulgação de projetos, sejam de pesquisa ou educacionais. Por ela, os projetos são divulgados e também buscam por apoio, por vezes financeiro, entre seus integrantes.

Ainda que em menor escala a Lista é utilizada assumidamente para encorajar outros professores ou pesquisadores a realizar estudos culturais.

\section{A Lista e seus Grupos de Interesse}

A Lista é um potente indicador dos interesses de pesquisa dos participantes. Tais interesses podem ser percebidos por meio dos artigos publicados, das discussões realizadas, dos temas de eventos anunciados, dos boletins divulgados, dos grupos estudados etc.

Cada grupo desses dados nos mostra uma perspectiva diferente dos interesses que atravessam a lista de discussões. Os artigos publicados em periódicos dizem de pesquisas completas, com algumas aberturas para futuras investigações. As discussões realizadas nos dão uma chave para os interesses teóricos e metodológicos do grupo. Os temas de eventos nos dizem da socialização de assuntos comuns. Em especial, há boletins que visam a um público de não pesquisadores.

No caso específico dos interesses de pesquisa dos subscribers, os grupos de interesse de pesquisa presentes na Lista parecem concentrar-se no estudo "do conhecimento do outro", nas "possibilidades da Etnomatemática na sala de aula" e na "Etnomatemática como possibilidade de produção de conhecimento".

\section{A Lista como Espaço Público-Político}

A Lista de Discussões compartilha pesquisas e estudos, e divulga eventos, textos e projetos em torno de temáticas que relacionam matemática e cultura. Ao compartilhar e divulgar, podemos entendê-la como um espaço político, e como espaço público, na medida em que pode ser tomada como um lugar em que se põe à mesa para uso comum. Em suma, podemos tomá-la como um espaço público-político em que diferentes exercícios de poder se presentificam, seja no modo como as discussões são travadas, seja na maneira como discutese a representatividade de diferentes países na organização do grupo de participantes. 
Esse espaço público-político é destacado também no modo como se entra e se sai da Lista. A Lista não seleciona seus integrantes e não possui um código de conduta. Dela participam professores, pesquisadores, interessados em matemática, em Etnomatemática, em cultura. Não há, tampouco, uma seleção operacionalizada em relação às áreas de atuação dos profissionais que dela participam. Pelo contrário, existe uma abertura ao outro de outra área, expressa em convites e incentivos. Ainda que os interesses mais destacados sejam aqueles associados à Educação Matemática, da Lista participam matemáticos, linguistas, artistas etc.

A Lista também demarca a importância política do papel do etnomatemático e, em especial, do NASGEm, nas suas regiões de atuação. Essa discussão esteve bastante presente no debate sobre a representação do grupo no México. Havia 20 anos que o grupo não possuía uma representação oficial no país, que é abarcado pela NASGEm. Havia, no entanto uma pesquisadora, membro do NASGEm e ativa na Lista, cujo trabalho de pesquisa em Etnomatemática se centrava naquele país. Um dos membros do NASGEm sugeriu sua nomeação como representante, o que gerou certa polêmica, uma vez que a pesquisadora não era nativa daquele país - porém ali trabalhava por mais de 10 anos.

É notável que nenhum participante da Lista duvidava da competência da pesquisadora nomeada, mas alguns membros questionaram a representação do outro, no caso mexicano. Sugeriu-se buscar por um mexicano para ocupar a posição, mas não houve voluntário. Surgia um impasse: "indicar um não-nativo para representar o outro" ou "não indicar ninguém, mantendo a posição vazia e sem representação"?. Essa discussão ganhou destaque por conta dos estudos dos participantes terem um cunho cultural e político.

Nos grupos de mensagens associados a esse tema, ao buscar-se um representante para o México demarcaram-se dois pontos bastante interessantes e, ao parecer do autor deste artigo, controversos. Explicitou-se, sem nenhuma reação contrária, que o candidato necessitaria falar inglês e que teria de ter condições de viajar aos EUA para participar das reuniões, uma vez que estas não poderiam ser custeadas pela associação. Tal cena pode indicar uma nucleação do grupo, algo próprio de espaços privados e hierarquizados, além de colocar em xeque questões há muito discutidas pela Etnomatemática acerca do empoderamento ${ }^{7}$ de culturas.

\section{A Lista e seus Movimentos de Teorização}

Nesta categoria discutimos movimentos de teorização da Etnomatemática, assim como discussões que dizem da teoria que sustenta essa região de inquérito e os modos como opera.

\footnotetext{
${ }^{7}$ Empoderamento é uma transliteração da palavra inglesa "empowerment", termo utilizado por Bishop (1988) com o sentido de reforçar um grupo politicamente.
} 
A Lista, de um modo geral, trata de um tema compartilhado - a Etnomatemática -, de uma forma naturalizada (não problematizada), o que pode indicar que: 1) o entendimento de Etnomatemática é convergente; ou 2) o entendimento de Etnomatemática se conforma por meio de seu uso.

Esse panorama, no entanto, se modifica em um momento específico da Lista, em que um pesquisador indiano propõe uma discussão a esse respeito, que surge por um de seus artigos ter sido recusado para participação no grupo de Ensino de Cálculo do $12^{\circ} \mathrm{ICME}$ (International Congress on Mathematical Education), em Seul. Seu artigo tratava de uma forma diferente de ensinar Cálculo, amparado por uma versão alternativa da história da matemática. Segundo o pesquisador, o Cálculo, como ensinado na maioria das escolas, está impregnado de ideias religiosas cristãs, o que considera um desrespeito e uma doutrinação, uma vez que o contexto de seu ensino na Índia, por exemplo, envolve outras religiões.

O núcleo de seu argumento assume que elementos matemáticos seguem crenças religiosas. Por exemplo, a continuidade seria contra o islamismo, a unicidade da lógica seria a favor do catolicismo, mas contra o budismo etc. Nessa perspectiva, matemática não é universal, o que, a princípio, iria ao encontro da defesa de muitos pesquisadores em Etnomatemática que a assumem como uma construção social.

Esse artigo foi avaliado por dois pareceristas, cujos pareceres foram discordantes. Ao final, o comitê do congresso indicou que o artigo teria seu lugar no grupo de trabalho em torno da Etnomatemática. $\mathrm{O}$ autor, indignado, lançou o caso à Lista.

Em sua argumentação, apontou a importância de se considerar que há outras matemáticas, e não colocar as "etnomatemáticas" como alternativas à Matemática Ocidental, para que esta não tenha um papel nuclear e aquelas um papel secundário. Indicou que seu caso reforçaria essa situação de hierarquia na medida em que uma história da matemática alternativa àquela mais aceita na comunidade não teve espaço em um congresso internacional, sendo tomada como de segunda categoria, inclusive por pesquisadores em Etnomatemática que estavam no comitê. Nesse panorama, questionou especificamente o que é Etnomatemática e a quê ela viria, interrogando a razão de a Matemática Cristã ser ensinada em diferentes países, independentemente de suas outras crenças religiosas.

No que se refere ao que é Etnomatemática, uma primeira resposta, compartilhada por alguns membros da Lista, diz que Etnomatemática é o estudo do pensamento matemático inato e de práticas que emergem de diferentes culturas. Desse modo nada haveria de missionário ou cristão em qualquer tipo de matemática. 
Tal afirmação parece trazer uma contradição implícita, se pensamos a matemática como construção enraizada culturalmente. Afinal, religiões são pilares fortes em diversas culturas. Negá-las de maneira tão contundente pode significar a negação da própria relação entre matemática e cultura, tão preciosa no discurso etnomatemático.

A polêmica se tornou mais acirrada em torno da construção histórica da matemática. Discutiu-se se a origem do Cálculo estava na Índia, na África ou na Europa. Independentemente da defesa de uma região ou de outra para tal berço, notamos um forte exercício de busca por UMA história da matemática com tendências universalizantes, sem que fosse vislumbrada a possibilidade do desenvolvimento de conceitos matemáticos paralelos. Tal atitude nos remete a uma tendência de linearização epistemológica do conhecimento. A Etnomatemática, então, não viria para trazer possibilidades para a história da matemática, mas como tentativa de trazer outra possibilidade - no singular - para essa história.

A discussão vai ainda além, ao questionar-se o próprio espaço da Etnomatemática. Entender etnomatemática(s) como matemática(s) alternativa(s), não colocando-as em destaque na escola, pode ser um indicativo que estas tenham um valor secundário.

A manutenção do conhecimento produzido pela Etnomatemática em um espaço restrito à própria Etnomatemática poderia, então, oferecer dois perigos. O primeiro, pedagógico, na medida em que esses conhecimentos deixam de operar no campo da escola de uma maneira generalizada. O segundo, epistemológico, podendo ser um indício de que os pesquisadores em Etnomatemática não consideram que possam defender suas ideias em outras áreas. Dessa forma, contrariamente ao seu discurso, a Etnomatemática serviria veladamente à marginalização de certos conhecimentos, colocando-os em certa redoma.

Uma segunda resposta sobre o que é e a que vem a Etnomatemática diz de sua potencialidade descolonizadora, na medida em que entendemos que a colonização deve ser distinguida de uma mera conquista física. A colonização pode ser compreendida de maneira mais abrangente, por envolver a captura da mente em termos ideológicos, com uma consequente internalização da ideologia do sistema colonial no grupo colonizado. Essa captura da mente se dá, dentre outras formas, pelo sistema educacional que doutrina. Além disso, esse sistema acaba sendo legitimado por uma falsa história da matemática - por muitos tomada como "A História da Matemática" - e pela ciência. A Etnomatemática, assim, poderia ser uma forma de descolonizar o sistema educacional, que se mantém com ideologia colonial mesmo depois da independência do país ex-colônia, ao trazer elementos que combatem a internalização dos efeitos do colonialismo. Por meio dela vislumbra-se uma possibilidade de 
desmaranhar o ninho que a Matemática Ocidental Acadêmica utiliza para dizer o que é e o que não é matemática nas diferentes culturas. Esse viés político-filosófico de um certo modo de assumir a Etnomatemática vai de encontro ao discurso de certa frente da Etnomatemática que busca um resgate cultural, na medida em que opera em um movimento inverso: o de destacar elementos culturais em uma matemática com base cultural híbrida.

Nesse panorama, podemos discutir a recusa do artigo submetido ao ICME em um grupo de ensino, transladando-o ao de Etnomatemática, tomando-a como um indício de que não se aceitou sua incorporação ao sistema educacional mais fortemente em vigor. Afinal, a aprovação do artigo no evento nos parece indicar que o artigo tinha solidez. A aceitação do artigo em um determinado grupo - o da Etnomatemática - nos parece restringir a circulação do texto a territórios já pré-determinados, à moda de uma concessão, por destoar de uma história da matemática tradicionalmente aceita. A própria discussão na Lista, em que um exercício de convencimento de versões da história da matemática se mostrava mais vigoroso do que uma abertura ao diálogo, nos leva a questionar quais são os mecanismos de legitimidade entre as histórias da matemática alternativas produzidas por etnomatemáticos. Em suma, haveria histórias da matemática "mais legítimas" que outras? Quem legitima uma ou outra? Como funcionam as relações de poder nesse grupo?

Uma terceira resposta se mostrou em uma das falas dos subscribers, que apontou a Etnomatemática como possibilidade de crítica e de desconstrução da universalidade da matemática. Sua função, então, seria, por um lado, descontruir aspectos universalizantes da matemática por meio de desvelamento ${ }^{8}$ de práticas culturais - sejam presentes ou passadas na fundação de conceitos matemáticos na história -, e, por outro, encontrar possibilidades pedagógicas para esses conceitos, de algum modo, desvelados.

Tomamos, aqui, a liberdade de sugerir que, nesta terceira resposta sobre o cerne da Etnomatemática, a decodificação fosse compreendida como "tornar um discurso inteligível", de modo que escapássemos da tentativa de "tradução" de uma prática. Uma decodificação seria, então, uma ampliação da visão de um horizonte de compreensões que fosse inteligível e compreensivo a outra cultura.

\section{Uma síntese de transição}

Após a abertura das quatro categorias abrangentes, voltamo-nos novamente à nossa interrogação "Para onde apontam as tendências e preocupações contemporâneas da pesquisa

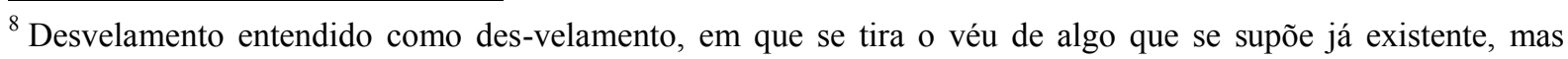
coberto.
} 
em Etnomatemática anunciadas na lista eletrônica de discussões do International Study Group on Ethnomathematics?", em busca de uma síntese de transição. Síntese, por se tratar de uma articulação dos aspectos significativos dos grupos de dados analisados e articulados, agora de modo panorâmico e holístico, à moda de uma paisagem, em que sua complexidade é assumida e detalhes deixam de ser meros detalhes, para virem a ser escolhas de figura em um fundo. De transição, por se tratar de um movimento de compreensão espaço-temporal que é sendo. Ela não se estagna, está em devir, quando se pensa que ela é, já foi, se mantendo como expressão no texto, mas mesmo assim, passível de compreensões em movimento, pois a cada leitura, o texto se articula com o leitor. Uma leitura não se faz apenas de texto, ou de leitor, mas é um fenômeno, um encontro leitor-humor-texto-local-tempo-etc., no qual o sentido se faz.

As quatro categorias articuladas, ainda que apresentadas de modo disjunto, se atravessam mutuamente. A Lista como mecanismo divulgador se dá em um espaço públicopolítico, por grupos que se organizam junto a interesses comuns, em torno de práticas enraizadas em concepções - veladas ou não - de Etnomatemática.

As preocupações presentes na Lista referem-se, em sua maioria, a questões bastante concretas e materiais, que buscam lidar com a permanência da Etnomatemática como área por meio de sua circulação. Assim, grande parte das mensagens ali trocadas tratam da divulgação do produzido por seus participantes.

Os grupos de interesse e estudo dos subscribers são bastante diversificados, o que nos parece bastante positivo, por mostrar que a pesquisa em Etnomatemática não se centra em nichos culturais específicos. Além disso, os grupos estudados vão além do critério de etnia, o que está em conformidade com o discurso d'ambrosiano que defende etno-matema-tica como algo muito maior do que "matemáticas de grupos étnicos", mas como uma proposta de programa que estuda

\footnotetext{
"instrumentos de reflexão, de observação, instrumentos materiais e intelectuais [que chamo ticas] para explicar, entender, conhecer, aprender para saber e fazer [que chamo matema] como resposta a necessidades de sobrevivência e de transcendência em diferentes ambientes naturais, sociais e culturais [que chamo etnos]". (D'AMBROSIO, 2002, p. 60, grifos do autor)
}

Os grupos de interesse de pesquisa presentes na lista parecem concentrar-se no estudo "do conhecimento do outro", nas "possibilidades da Etnomatemática na sala de aula" e na "Etnomatemática como possibilidade de produção de conhecimento".

Se tomamos uma categorização dos interesses de pesquisa em Etnomatemática criada a partir de discussões que se debruçaram sobre essa intenção há alguns anos, com base em Shirley (2012), Miarka (2012) e D'Ambrosio (2002) (vide Quadro 03), percebemos que 
algumas tendências de pesquisa em Etnomatemática outrora importantes no discurso etnomatemático podem estar se enfraquecendo, tais como "Etnomatemática para trabalhar situações que envolvem o encontro cultural, "Etnomatemática e o pensar sobre as próprias bases" e "Etnomatemática para desconstruir uma visão linear da história da matemática".

Quadro 03: Grupos de interesse da pesquisa em Etnomatemática

\begin{tabular}{|c|l|}
\hline Autor & Grupos de interesse na pesquisa em Etnomatemática \\
\hline & 1) Etnomatemática como busca pelo conhecimento do outro \\
Shirley (2012) Etnomatemática na sala de aula & 3) Etnomatemática para trabalhar situações que envolvem o encontro cultural \\
& 4) Etnomatemática e o pensar sobre as próprias bases \\
\hline Miarka (2012) & 5) Etnomatemática como possibilidade de produção de conhecimento \\
\hline D'Ambrosio (2002) & 6) Etnomatemática para desconstruir uma visão linear da história da matemática \\
\hline
\end{tabular}

Fonte: Elaborado pelo autor.

Por fim, as categorias "A Lista como espaço público-político" e "A Lista e seus atravessamentos teóricos" nos possibilitaram problematizar a atividade realizada na Lista.

Gostaríamos de voltar a destacar duas cenas bastante significativas presentes na Lista: a da eleição por um representante do NASGEm no México e a indicação de um artigo que versava sobre questões de ensino de matemática e cultura para compor um grupo de trabalho específico de Etnomatemática e não um de ensino em geral.

Essas duas situações lidam com temas que podem ser compreendidos como próprios das categorias de interesse propostos na Tabela 02 e que não são assumidos na Lista: "Etnomatemática para trabalhar situações que envolvem o encontro cultural" - por lidar com questões de representatividade do outro em uma dinâmica de encontro entre pesquisadores e pesquisados -, e "Etnomatemática e o pensar sobre as próprias bases" - pela possibilidade de se questionar a razão de alguns temas outrora caros à Etnomatemática não estarem frequentemente presentes na Lista, e "Etnomatemática para desconstruir uma visão linear da História da Matemática" - pela possibilidade de questionar os mecanismos de legitimação de histórias alternativas no maior evento da área.

Com isso, nos demos conta de diferentes exercícios de poder presentificados naquele espaço, que podem ser analisados junto ao discurso originário da Etnomatemática, em que entendemos origem como "evidência original", expressão utilizada por Husserl (1970) para indicar uma série de articulações que se amalgamam de modo a expressar um significado que se mantém, a partir de uma emergência de significado que não ocorre por meio de um criador, mas em uma conjuntura. 
Em seu discurso originário, a Etnomatemática se mostra como um movimento de desconstrução de verdades, sejam elas relacionadas à História da Matemática ou à própria Matemática, assumindo a dimensão cultural na construção do conhecimento matemático. Pouco a pouco, no entanto, ela se conforma como uma área de destaque, em que se acumulam saberes. A ideia de área pode também ser entendida como território com fronteiras a defender.

A força da Etnomatemática - nos parece - não reside em seus movimentos de ruptura, nem na sua possibilidade como área. A etnomatemática como movimento - aquela com $e$ minúsculo - é combustível para aquela da área com $E$ maiúsculo, que traz visibilidade para o movimento, na mesma medida em que a Etnomatemática se torna uma morada possível para que movimentos etnomatemáticos ocorram. Sua força, entendida assim, se dá em um processo de simbiose - ou seria de duelo? - entre área e movimento.

A Lista nos parece defender com certa maestria as possibilidades da Etnomatemática como território, porém destacamos a importância de atentarmo-nos aos movimentos que ali ocorrem, como possibilidade para a invenção em Etnomatemática.

\section{Referências}

BICUDO, Maria Aparecida Viggiani. A Contribuição da Fenomenologia para a Educação. In: BICUDO, Maria Aparecida Viggiani (Org). Fenomenologia uma visão abrangente da Educação. São Paulo: Olho D'água, 1999.

BICUDO, Maria Aparecida Viggiani. Pesquisa em Educação matemática: concepções e perspectivas. In: BICUDO, Maria Aparecida Viggiani. Filosofia da Educação matemática: Um Enfoque Fenomenológico. São Paulo: Editora UNESP, 1999a.

BISHOP, Alan. Mathematical Enculturation: A Cultural Perspective on Mathematics Education. Dordrecht: Kluwer Academic Publishers, 1988.

CNPQ. Diretório dos Grupos de Pesquisa no Brasil. Disponível em: $<$ http://dgp.cnpq.br/buscaoperacional/>. Acesso em: 15 fev. 2014

CNPQ. Diretório dos Grupos de Pesquisa no Brasil. Disponível em: $<$ http://dgp.cnpq.br/buscaoperacional/>. Acesso em 20 set. 2012

D'AMBROSIO, Ubiratan. Etnomatemática: elo entre as tradições e a modernidade. Coleção Tendências em Educação Matemática. Belo Horizonte: Autêntica, 2002.

D'AMBROSIO, Ubiratan. Socio-Cultural Bases for Mathematical Education. In: INTERNATIONAL CONGRESS IN MATHEMATICS EDUCATION, 5th, Adelaide, 1984. Proceedings... Adelaide, 1984.

HUSSERL, Edmund. The Origin of Geometry. In: HUSSERL, Edmund. The Crisis of European Sciences. Evanston: Northwestern University Press, 1970.

ISGEM. Main Page. 2016. Disponível em: < http://isgem.rpi.edu>. Acesso em: 12 abril de 2016. 
MARTINS, Joel; BICUDO, Maria Aparecida Viggiani. A Pesquisa Qualitativa em Psicologia: fundamentos e recursos básicos. São Paulo: EDUC, 1989.

MIARKA, Roger. Etnomatemática, por onde andas e a quê vens? In: LIMA, Angela Maria de Sousa et al. Inclusão: debates em diferentes contextos. Londrina: Universidade Estadual de Londrina, 2012.

SHIRLEY, Lawrence. The Work of Ethnomathematics. In: CONGRESSO BRASILEIRO DE ETNOMATEMÁTICA, 4, Belém. Anais... Belém, 2012. 